\title{
From Brain Drain to Knowledge Transfer: Experiences of the Italian Academe
}

\author{
Arturo Galan* and Tommaso Agasisti**
}

Massification, the pressures of accountability, competition to attract the best local and international students, worldwide quality rankings and difficulties in attracting and retaining and researchers are challenges faced by tertiary eduction sectors in many countries (Altbach et al., 2012). The Italian tertiary education sector is no different. A consideration of some of the issues and challenges that the Italian tertiary education sector faces provides crucial context to a study on knowledge transfer and of elite professional mobility between Italy and Australia.

Italy has a reputation for high-quality university training, and this renders its graduates attractive to universities and research institutes outside Italy. The USA, Australia and the United Kingdom are among the destinations preferred by Italian researchers. This paints the typical picture of braindrain. It appears, however, that Italy has difficulties integrating qualified academic researchers from abroad, as it suffers from a negative flow rate where the emigration of academics exceeds the immigration of academics (Beltrame, 2007; OECD, 2005; Dumont et al., 2010). This suggests that in addition to brain drain there is also the problem of a lack of brain circulation: it is difficult for Italian expatriates to return to the Italian university system, (CENSIS, 2002). Policy responses that favour greater quality and international competitiveness of Italian universities could contribute to attracting both more academics (professors and researchers) and more talented students on the international level. Such policies would constitute an investment in knowledge transfer.

These significant considerations are reflected in the research that this article presents. This research includes our own empirical research project which used a semi-structured questionnaire (Patton, 2002), and a sample of 82 Italian professors and researchers to elicit data in two fundamental areas: (a) the reasons for academics to leave Italy; and (b) the problems in attracting talented academics from abroad. Based on the analysis of the responses, the project also proposes policies for improving the quality and attractiveness of Italian universities.

Brain drain is difficult to quantify and define. Beltrame (2007) notes that the majority of researchers use it to refer to subjects with a higher education qualification and who live and work in a country different from their native country. However, this definition does not resolve various problems when approaching the subject, such as differences between brain drain, brain exchange and brain circulation. Conversely, in our study, we refer to the brain drain that takes place in a particular subset of population: the Italian academics or researchers who seek a future outside Italian borders.

Dumont et al. (2010) estimate the total rate of Italian expatriates at 5.22 per cent, rising to 7.07 per cent for people with university training, This is considered to be medium-to-low and below the European average, and suggests that the "drain" is not such a serious problem. However, if the "drain" is compared to the "gain", Italy is not as competitive as other EU countries. As Beltrame (2007: 41) states:

\footnotetext{
* UNED, Madrid.

** DIG, Milan.
} 
The data seems to support the thesis that the Italian problem is not the size of the drain (...), but rather that it is based more on the scant capacity for attraction, the reason that Italy is unable to compensate for its losses.

The causes that drive Italian academics to emigrate are varied. Our study identified six main reasons that justified exit from Italy for a high percentage of those surveyed. We attribute three to exogenous reasons, namely (1) lack of opportunities and prospects in Italy; (2) bad working conditions, such as a low or zero salary and very small investment in research; and (3) a low ethical level (lack of a meritocratic recruitment and professional development practices; high levels of professional endogamy; lack of independence and competitiveness, and failure to consider the situation of young researchers). These factors relate to the reality of Italian universities. On the other hand the three endogamous reasons relate to the personal interests of the subjects: the higher quality of scientists and scientific research undertaken abroad; attractive post-doctorial offers outside Italy; and a desire for international experience.

The responses with the highest descriptive and emotional load referred to the lack of an ethical system of hiring and promotion in Italian universities. Expatriate professors showed their disagreement with the policies and habits of academics in Italy. Thus terms such as nepotism recurred, combined with a lack of objective criteria for evaluation based on merit, meaning that the power of the candidate's family is more important than his or her curriculum vitae.

The principal countries receiving Italian 'brains', according to the Organization for Economic Co-Operation and Development (OECD) (2005), are the USA (32\%), Australia (13.6\%), Canada $(12.6 \%)$, France $(9.3 \%)$, United Kingdom (8\%), Switzerland (6.9\%) and Germany (6.2\%).

Databases for associations and web portals also offer an idea of the volume of flows out of Italy. The largest database, the Italian Scientists and Scholars of North America Foundation (ISSNAF), has almost 2000 affiliates in the United States and Canada. In Australia, there is an association of Italian researchers, the Association for Research between Italy and Australia ('ARIA'), which attempts to connect Italian academics residing in Australia and to make them more visible, but it has few members. To carry out further investigation, we used the Database Accessible Via the Internet ('DAVINCI') which lists Italian researchers who are not residing in Italy and who are employed by foreign universities, research centres or international organizations. DAVINCI is run by the Italian Ministry of Foreign Affairs and in 2010 it listed 2,546 Italian researchers working abroad. Although it is a voluntary portal, the distribution by country of the researchers it lists provides an idea of the preferred destination countries of Italian researchers. 575 academics $(23 \%)$ are in the USA, 374 in Brazil (15\%), 252 in Great Britain (10\%), 243 in Germany (10\%), 169 in Switzerland (7\%), 126 in Belgium (5\%), 120 in France (5\%), 116 in Australia (5\%) and 77 in Canada (3\%).

Reflecting the scant capacity to attract Italian and foreign academics, the vast majority of the Italian professoriate in our study sample $(80 \%)$ were not planning to return to Italy. Their reasons for not returning were closely connected with those given for emigrating and with the attractiveness of Italian universities to foreign professors. When asked directly whether Italy was able to attract talented foreign professors, the general answer was negative: the main reasons offered were as follows:

- low wages, no 'moving' packages that, for example, improved original conditions

- inferior research funds, infrastructures, laboratories and networks

- no international competitiveness

- no clear career path and corrupted environment

- language

- bureaucratic burdens: it is almost impossible to enter the Italian system as an outsider.

With respect to salary, Altbach, Reisberg and Pacheco's (2012) study on worldwide academic salaries reflects our study's findings. It found that after adjusting average gross monthly salary by 
GRAPH 1

AVERAGE EVALUATION OF CHARACTERISTICS OF THE ITALIAN UNIVERSITY

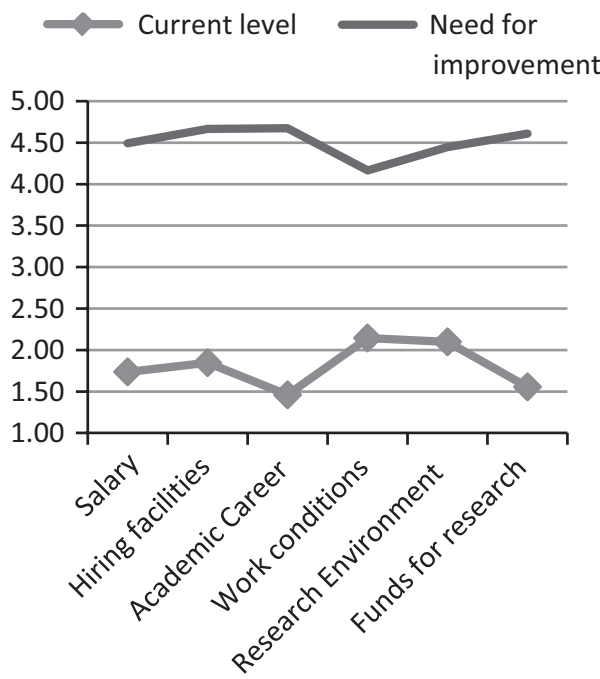

purchasing power parity (PPP), Italy occupies second place worldwide at $\$ 6,955$ ( $\$ 1,000$ above the USA). However considering salary at the beginning of the academic career means that Italy then drops to ninth place at $\$ 3,525$ ( $\$ 1,500$ beneath the USA). These comparisons require more in-depth study because in the USA salaries vary considerably between top universities and the rest, which is something that does not occur in Italy.

The unattractiveness of Italian universities generally was illustrated vividly in our study by the responses from the sample subjects when asked to evaluate, using a 5-point Likert scale, the importance of six basic elements of a university's attractiveness: salary, hiring facilities, academic career, work conditions, research environment, funds for research. These are presented in Graph 1.

The responses were definitive: the present situation in Italy is considered highly deficient in all aspects, especially with regard to the academic career and funds available for research. Thus the need for change is almost at its greatest as there is a clear perception that there is much to be undertaken. Further, the responses were very homogenous, with no statistically significant differences or appreciable effects due to country of emigration, professional category or years of experience.

Considering the total population size of destination countries, Australia, at 21 million people (compared with 316 million people in the USA), plays a relatively strong role in attracting Italian brains. This could be because its universities rank highly in global league tables. For example, one half of its universities are included in the international top universities league, such as The Times Higher Education World Ranking Times. The criteria used by the Lisbon Council University Systems Ranking (Ederer et al., 2008), such as inclusiveness, access, effectiveness, attractiveness, age range and responsiveness, to rank the university systems of 17 OECD countries, also reflects very positively on the Australian university system. Australia is ranked first, followed by the United Kingdom and Denmark, while the USA is in fifth place. Italy is ranked ninth of 17 countries. Australia ranks first in terms of participation in higher education, second in the use of tertiary education as lifelong learning institution, and fourth in the ability to attract foreign students.

In conclusion, the results of our study show considerable agreement in the descriptions of the problems that face the Italian university system that seeks to become more competitive and internationally attractive. Our study noted that key aspects for guaranteeing competitiveness related 
to salary, academic career possibilities, recruitment, career development, and funding for research. Conversely, Australian universities appear to rank highly in international university rankings. For a country with a relatively small population, Australia has attracted a significant number of Italian academics.

Cultural and ethical changes are needed to enable the Italian system to attract academic talent, and to attract it back to Italy, and to ensure that it benefits from its circulation. The extent to which policies can facilitate greater openness, transparency and objectivity in the evaluation, selection and promotion of faculty, allowing for greater flexibility in the hiring of personnel from abroad and enabling differentiation of salaries and working conditions as a function of the performance of professors and departments, will be the key.

\section{REFERENCES}

Altbach, P.G., L. Reisberg, and I.F. Pacheco

2012 "Academic Remuneration and contracts", in P.G. Altbach, L. Reisberg, M. Yudkevich, G. Androushchak and I.F. Pacheco (Eds), Paying the Professoriate: A Global Comparison of Compensation and Contracts. Routledge, London.

Beltrame, L.

2007 "Realtà e retorica del brain drain in Italia. Stime statistiche, definizioni pubbliche e interventi politici" [Reality and rhetoric of brain drain in Italy. Statistical estimates, public definitions and political interventions]. QUADERNO 35. Ed. Dipartimento Di Sociologia E Ricerca Sociale. Quaderni.Università Degli Studi di Trento (accessed 20 April 2012).

CENSIS

2002 Un capitale intellettuale da valorizzare: indagine conoscitiva sul fenomeno della fuga dei cervelli all'estero. Rapporto finale [Valuable intellectual capital: cognitive investigation of the phenomenon of brain drain abroad]. CENSIS, Rome.

Dumont, J.C., G. Spielvogel, and AND S. Widmaier

2010 "International Migrants in Developed, Emerging and Developing Countries: An Extended Profile", OECD Social, Employment and Migration Working Papers No.114.

Ederer, P., P. Schuller, and S. Willms

2008 University Systems Rankings: Citizens and Society in the Age of Knowledge, The Lisbon Council Policy Brief. Accessed January 12, 2012. http://www.lisboncouncil.net/publication/publication/ 38-university-systems-ranking-citizens-and-society-in-the-age-of-knowledge.html

OECD

2005 Database on immigrants and expatriates. http://www.oecd.org/migration/mig/databaseonimmig rantsinoecdcountriesdioc.htm (accessed 8 November 2012).

Patton, M.Q.

2002 Qualitative Research \& Evaluation Methods, 3rd edn.. Sage Publications, Thousand Oaks, CA. 